\title{
Effects of physical growth conditions on the structural and optical properties of sputtered grown thin $\mathrm{HfO}_{2}$ films
}

\author{
Gulnur Aygun ${ }^{\mathrm{a}, *}$, Ayten Cantas ${ }^{\mathrm{a}}$, Yilmaz Simsek ${ }^{\mathrm{a}}$, Rasit Turan ${ }^{\mathrm{b}}$ \\ a Department of Physics, İzmir Institute of Technology, Gülbahçe Campus, TR-35430 Urla-i̇MíR, Turkey \\ b Department of Physics, Middle East Technical University, TR-06531 Ankara, Turkey
}

\section{A R T I C L E I N F O}

Available online 31 December 2010

\section{Keywords:}

$\mathrm{HfO}_{2}$

Reactive DC sputtering

XPS depth profiling

Spectroscopic ellipsometer

FTIR

XRD

\begin{abstract}
A B S T R A C T
$\mathrm{HfO}_{2}$ thin films were prepared by reactive DC magnetron sputtering technique on (100) $p$-Si substrate. The effects of $\mathrm{O}_{2} / \mathrm{Ar}$ ratio, substrate temperature, sputtering power on the structural properties of $\mathrm{HfO}_{2}$ grown films were studied by Spectroscopic Ellipsometer (SE), X-ray diffraction (XRD), Fourier transform infrared (FTIR) spectrum, and X-ray photoelectron spectroscopy (XPS) depth profiling techniques. The results show that the formation of a $\mathrm{SiO}_{x}$ suboxide layer at the $\mathrm{HfO}_{2} / \mathrm{Si}$ interface is unavoidable. The $\mathrm{HfO}_{2}$ thickness and suboxide formation are highly affected by the growth parameters such as sputtering power, $\mathrm{O}_{2} / \mathrm{Ar}$ gas ratio during sputtering, and substrate temperature. XRD spectra show that the deposited films have (111) monoclinic phase of $\mathrm{HfO}_{2}$, which is also supported by FTIR spectra. XPS depth profiling spectra shows that highly reactive sputtered $\mathrm{Hf}$ atoms consume some of the oxygen atoms from the underlying $\mathrm{SiO}_{2}$ to form $\mathrm{HfO}_{2}$, leaving $\mathrm{Si}-\mathrm{Si}$ bonds behind.
\end{abstract}

(c) 2010 Elsevier B.V. All rights reserved.

\section{Introduction}

In order to overcome the scaling limit of conventional Si-based insulators, high permittivity (high- $\kappa$ ) materials are being developed as alternative dielectrics. Having high- $\kappa$ value around 25 and being thermodynamically stable when grown on $\mathrm{Si}, \mathrm{HfO}_{2}$ is considered to be the most promising candidate to replace $\mathrm{SiO}_{2}$ [1]. Important film properties including dielectric constant and refractive index of grown thin oxide film depend on the growth parameters [2] as well as the initial thin film constitution [3]. Moreover, the interfacial properties of grown film play crucial role in the electrical properties of the devices [4]. Therefore, it should be noted that the applied physical conditions must be well controlled through the film growth processing steps in order to improve the grown film's dielectric properties.

A number of various film growth techniques have been used to fabricate high- $\kappa$ materials such as thermal oxidation [5], a variety of chemical vapor deposition techniques [6], ion beam deposition [7], atomic layer deposition [8], pulsed laser deposition [9], laser oxidation [10], remote plasma oxidation [11], DC and RF sputtering [5,12]. Since each method has some advantages and disadvantages, it is not yet clear which method would be the best choice for device applications.

This paper presents reactively grown $\mathrm{HfO}_{2}$ thin film by DC sputtering technique on $p$-Si (100) substrate with native oxide. The optical and structural characteristics of grown thin hafnium-oxide films were studied with a few characterization techniques in a more

\footnotetext{
* Corresponding author.

E-mail address: gulnuraygun@iyte.edu.tr (G. Aygun).
}

detailed manner to understand the effect on the grown film's properties of physical growth conditions.

\section{Experimental procedure}

$\mathrm{HfO}_{2}$ thin film was grown on $\mathrm{Si}$ substrate by reactive DC magnetron sputtering technique. $p$-type Si (100) substrate with resistivity of 7-17 $\Omega \mathrm{cm}$ was cleaned chemically in boiling trichloroethylene, acetone with ultrasonic bath, and rinsed with ultrapure water. After drying the wafer with pure $\mathrm{N}_{2}$ gas, it was mounted onto the substrate holder having a $7.4 \mathrm{~cm}$ distance to the target of magneto sputtering deposition chamber vacuumed with a Turbo Molecular Pump (TMP). A 2" diameter with 0.25 " thick of $99.9 \%$ pure hafnium target was used. It was pre-sputtered for 3 min with Ar gas to remove the possible surface contamination of target. $30 \mathrm{sccm}$ Ar gas flow was used for all processes. In order to get the required gas ratio, i.e. $\mathrm{O}_{2} / \mathrm{Ar}$, oxygen gas flow was changed correspondingly. Base pressure of sputtering chamber was below $2 \times 10^{-6}$ Torr while working pressure during the sputtering was $0.44 \times 10^{-3}$ Torr. Prior to, as well as during deposition, the substrate was heated by a halogen lamp and the substrate's temperature was adjusted by a temperature controller. Sputtering time duration was 5 min for the growth processes. Thin film deposition rate can be controlled by both the DC source and gas flow level of reactive $\mathrm{O}_{2}$ and $\mathrm{Ar}$ gas mixture (Fig. 1).

Spectroscopic Ellipsometer (SE) measurement of thin $\mathrm{HfO}_{2}$ film on $p$-Si (100) was made in the wavelength range of 300-850 $\mathrm{nm}$ with an in-situ Sentech SE-801. In-situ SE measurement at $70^{\circ}$ incident light beam on the sample surface was realized to obtain the characteristic parameters obtained by SE, i.e. DELTA and PSI. SpectraRay program 


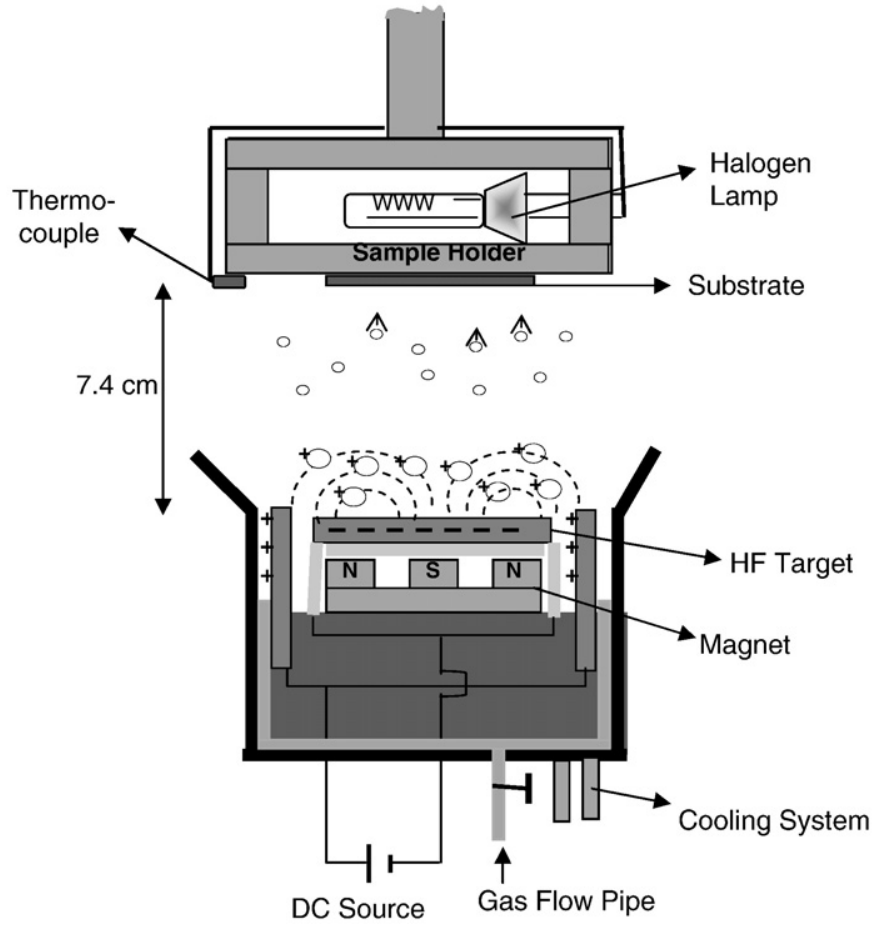

Fig. 1. Inside view of the sputtering chamber with sample holder used for DC sputtering method.

was used for modeling and fitting processes of the SE data from the wavelength range from 350 to $850 \mathrm{~nm}$. The outcomes of this process were refractive index $(n)$, thickness $(d)$, absorption $(\kappa)$ and transmission of measured film.

Chemical composition and the structure of oxide films were examined by a FTIR spectrometer (BRUKER Equinox 55). X-ray diffraction (XRD) pattern was measured by a Rigaku Miniflex system equipped with $\mathrm{CuK}_{\alpha}$ radiation of average wavelength 1.541 A. The XRD pattern was analyzed in terms of observed peak positions at specific $2 \theta$ values and relative intensities of the peaks by means of a computer software equipped with an ICDD database.

X-ray Photoelectron Spectroscopy (XPS) measurements were realized with a SPECS EA200 (Electron Spectroscopy for Chemical Analysis) system equipped with a hemispherical electron analyzer at a take off angle of $90^{\circ}$. Excitation source was monochromatic $\mathrm{AlK}_{\alpha}$ line with a power of $490 \mathrm{~W}$. The pressure was $7.5 \times 10^{-10}$ Torr. The film surface was sputtered by $\mathrm{Ar}^{+}$ions having the energy of $2000 \mathrm{eV}$ with totally 19 etching cycles (etched layer numbers) each lasted for $3 \mathrm{~min}$. XPS measurements were done with $96 \mathrm{eV}$ pass energy and $0.1 \mathrm{eV}$ step size. Binding energies were corrected with respect to $C 1$ s peak at $284.6 \mathrm{eV}$ and Si 2p peak at $99.3 \mathrm{eV}$, respectively, for the surface and depth layers. Background correction and peak fitting procedures were performed using CASA XPS software.

\section{Basic theory of spectroscopic ellipsometer}

Ellipsometer is principally based on the change in polarization state during reflection off of a light from a film surface at an oblique angle of incidence, $\varphi[13,14]$. The incident light at the planar interface is defined with an optical plane wave:

$E=E_{i n c}=E_{p, i n c}+E_{s, i n c}$
The amplitude ratio of reflection coefficients in terms of optical plane wave components are given as;

$r_{p}=\frac{E_{p, r e f l}}{E_{p, \text { inc }}}$ and $r_{s}=\frac{E_{s, \text { refl }}}{E_{s, \text { inc }}}$

Complex reflection ratio, $\rho$, is obtained as an outcome of matching the electric and magnetic fields at the interface between different materials;

$\rho=\frac{r_{p}}{r_{s}}=\frac{\left|r_{p}\right|}{\left|r_{s}\right|} e^{i\left(\delta_{p}-\delta_{s}\right)}=\tan \Psi e^{i \Delta}$

where $\psi, \Delta$ and $\rho$ are the parameters of an ellipsometer measurement.

Furthermore, complex refractive index, $N=n+i k$, and dielectric constant, $\varepsilon=\varepsilon_{1}+i \varepsilon_{2}$, describe the optical properties of any medium. $n$ and $k$ are called the refractive index and extinction coefficient, respectively. Relations between real and imaginary parts of complex refractive index and dielectric constant are given by:

$\varepsilon_{1}=n^{2}-k^{2}$ and $\varepsilon_{2}=2 n k$

$k=\frac{\lambda}{4 \pi} \alpha$

$I(x)=I_{0} e^{-\alpha x}$

where $\alpha$ is absorption coefficient of material, and $I$ is intensity of light in the dielectric material from which light is passing through. The 5 parameters, $n, k, \varepsilon_{1}, \varepsilon_{2}$ and $\alpha$ define the optical characteristics and they are, in the mean time, related to the electronic properties of the medium.

The relation between optical and electrical parameters of bulk materials [14] is found as:

$\varepsilon=\varepsilon_{1}+i \varepsilon_{2}=\sin ^{2} \varphi\left[1+\tan ^{2} \varphi\left(\frac{1-\rho}{1+\rho}\right)^{2}\right]$

\section{Results and discussion}

\subsection{FTIR spectra of DC sputtered $\mathrm{HfO}_{2}$ films}

Fig. 2 shows FTIR spectra of Hf oxide films grown at 100, 150, and $200{ }^{\circ} \mathrm{C}$ for $5 \mathrm{~min}$ with $\mathrm{O}_{2} / \mathrm{Ar}$ gas ratio of 0.4 applying $30 \mathrm{~W}$ of $\mathrm{DC}$

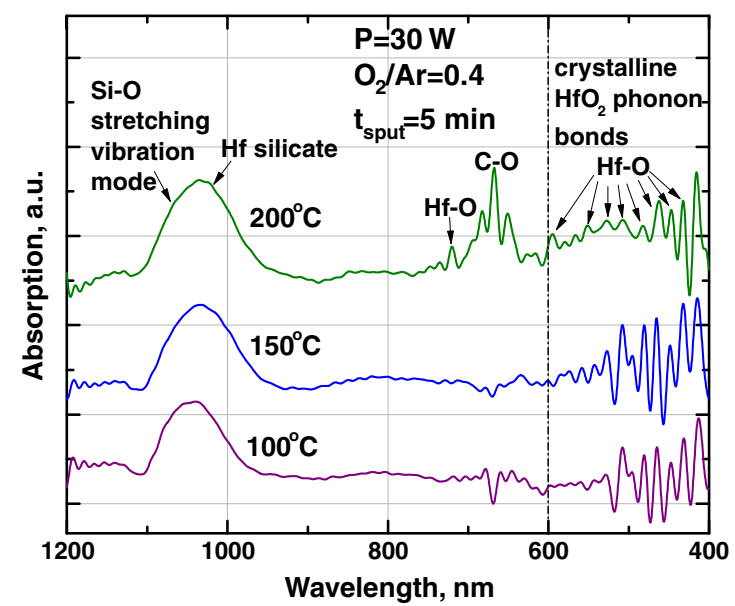

Fig. 2. FTIR spectra obtained from $\mathrm{Hf}$ oxide films grown at 100,150 , and $200{ }^{\circ} \mathrm{C}$ with $\mathrm{O}_{2} / \mathrm{Ar}$ gas ratio of 0.4 for $5 \mathrm{~min}$ at $30 \mathrm{~W}$ of $\mathrm{DC}$ sputtering power. 
sputtering power. The spectra were taken between 400 and $1200 \mathrm{~cm}^{-1}$, since the low wavenumber region $\left(<1100 \mathrm{~cm}^{-1}\right)$ is more important for detection of hafnium-oxide-related bonds.

It is clearly observed for all three substrate temperatures that not only broad but also very intense absorption band standing between 950 and $1120 \mathrm{~cm}^{-1}$ can be decomposed into two intensive peaks located at the vicinity of 1070 and $1020 \mathrm{~cm}^{-1}$ corresponding, respectively, to $\mathrm{Si}-\mathrm{O}$ stretching vibration mode and hafnium silicate $\left(\mathrm{HfSi}_{\mathrm{x}} \mathrm{O}_{\mathrm{y}}\right)$ [15]. The total broad-band peak's intensity increases as well as a slight shift to lower wavenumber regions as a result of substrate temperature increments ranging from 100 to $200^{\circ} \mathrm{C}$ is realized. Since the peak intensity reflects the film thickness, it can be deduced that the thickness of hafnium silicate layer increases when the substrate temperature is increased. Having very close location but not at the expected exact position of natural oxide of $\mathrm{SiO}_{2}\left(1075 \mathrm{~cm}^{-1}\right)$, however, implies that this interfacial oxide layer is in the form of suboxide of $\mathrm{Si}$, i.e. $\mathrm{SiO}_{\mathrm{x}}$ with $\mathrm{x}<2$, instead of natural oxide form [6]. A slight shift to lower wavenumber region corresponds to transforming of natural $\mathrm{SiO}_{2}$ interfacial layer to suboxide form of $\mathrm{Si}$ as a result of substrate temperature increments.

The main FTIR peaks reflecting $\mathrm{Hf}-\mathrm{O}$ bonds are getting recognized well when the substrate temperature increases. It is given in the literature that the main peaks around 595, 551, 527, $507 \mathrm{~cm}^{-1}$ are due to $\mathrm{Hf}-\mathrm{O}$ chemical bonds, so does $720 \mathrm{~cm}^{-1}$ one [16,17]. It is obvious from the figure that $720 \mathrm{~cm}^{-1}$ peak is only recognized in $200{ }^{\circ} \mathrm{C}$ grown film, while not even definite with lower substrate temperature ones. Therefore, it can be commented on this reality that $\mathrm{Hf}-\mathrm{O}$ chemical bonds are not even traced when growth process takes place below $200{ }^{\circ} \mathrm{C}$ substrate temperature. It is reported also that the presence of sharp $\mathrm{HfO}_{2}$ phonon bonds in the low wavenumber region $\left(600-400 \mathrm{~cm}^{-1}\right)$ is the result of crystalline structure of the grown films [18]. Since these defined peaks between 400 and $600 \mathrm{~cm}^{-1}$ are well captured in $200{ }^{\circ} \mathrm{C}$ substrate temperature grown film, we can comment that not only $\mathrm{Hf}-\mathrm{O}$ phonon bonds recognized when the substrate temperature increases but also the crystallization occurs at the same time.

Even though the most intensive features of $\mathrm{HfO}_{2}$ are reported in the $100-500 \mathrm{~cm}^{-1}$ region, most of which extend outside of our measurement range (lower than $400 \mathrm{~cm}^{-1}$ ) [17].

Since FTIR measurement was done in air, as a result, the $\mathrm{C}-\mathrm{O}$ vibration mode is detected as well at $670 \mathrm{~cm}^{-1}$ of its expected position [19].

\subsection{XRD structural properties}

XRD spectra obtained from $\mathrm{Hf}$ oxide films grown at 100,150, and $200{ }^{\circ} \mathrm{C}$ with $\mathrm{O}_{2} / \mathrm{Ar}$ gas ratio of 0.4 for $5 \mathrm{~min}$ at $30 \mathrm{~W}$ of DC sputtering power is plotted in Fig. 3. X-ray diffraction (XRD) of $\mathrm{HfO}_{2}$ sputter grown films on $p$-type (100) $\mathrm{Si}$ with natural $\mathrm{SiO}_{2}$ oxide was performed at room temperature in the measurement range for $2 \theta$ from 10 to $65^{\circ}$.

It is obvious that the film grown at $100{ }^{\circ} \mathrm{C}$ is mainly amorphous while a very tiny poly-crystalline structure starts to be recognized for $\mathrm{HfO}_{2}$. Its intensity increases very tiny for $150{ }^{\circ} \mathrm{C}$, while it is recognizable enough at $200{ }^{\circ} \mathrm{C}$ substrate temperature grown film. This peak observed around $28^{\circ}$ of $2 \theta$ attributed to (111) monoclinic phase of $\mathrm{HfO}_{2}$ [17,20-23]. Nevertheless, having a low peak intensity and high FWHM value, it can be inferred that the microcrystalline structure has just been started to be formed. Pereira et al. studied the sputter grown $\mathrm{HfO}_{2}$ thin film's structural analysis using XRD with respect to substrate temperature during growth from the room temperature to $200{ }^{\circ} \mathrm{C}$ [20]. Even though amorphous structure was detected at room temperature growth process, they also recognized a peak around $28^{\circ}$ for $2 \theta$ when the substrate temperature was increased to $200^{\circ} \mathrm{C}$.

The other two intensive peaks around $33.3^{\circ}$ and $62.1^{\circ}$ in Fig. 3 are the signals coming from the $\mathrm{Si}(100)$ substrate underlying thin hafnium oxide film. This microcrystalline structure of $\mathrm{HfO}_{2}$ film grown

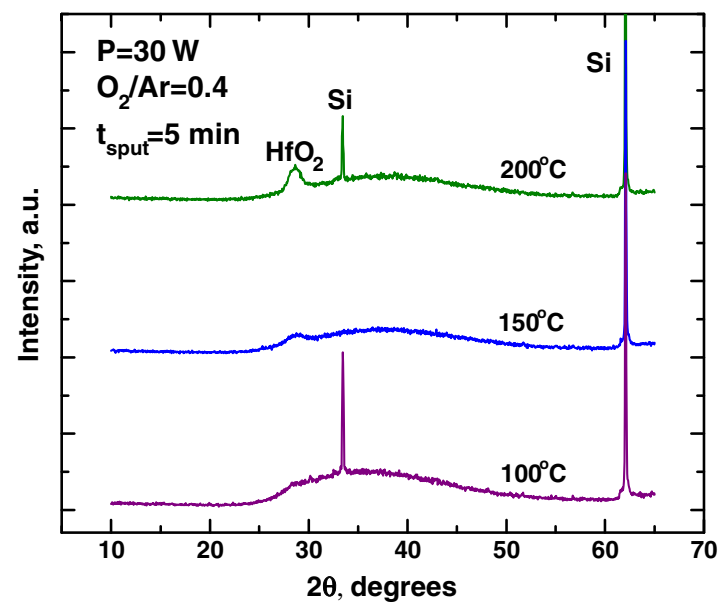

Fig. 3. XRD spectra obtained from $\mathrm{Hf}$ oxide films grown at 100,150 , and $200{ }^{\circ} \mathrm{C}$ with $\mathrm{O}_{2} / \mathrm{Ar}$ gas ratio of 0.4 for $5 \mathrm{~min}$ at $30 \mathrm{~W}$ of DC sputtering power.

at $200{ }^{\circ} \mathrm{C}$ can also be predicted from the sharpness of phonon spectrum in the 400 to $600 \mathrm{~cm}^{-1}$ region of FTIR spectrum as seen in Fig. 2 [18].

\subsection{XPS depth profiling spectrum for chemical analyses}

XPS depth profiling spectra obtained from Hf oxide film grown at $200{ }^{\circ} \mathrm{C}$ with $\mathrm{O}_{2} / \mathrm{Ar}$ gas ratio of 0.4 for $5 \mathrm{~min}$ at $30 \mathrm{~W}$ of DC sputtering power are shown in Fig. 4(a) for $\mathrm{Hf} 4 f$ and (b) for Si $2 p$ spectrum. It is obvious from Fig. 4(a) that all levels containing hafnium-oxide can be decomposed into two main peaks. This situation for $\mathrm{HfO}_{2}$ is explained as a spin-orbit splitting of $1.6 \mathrm{eV}$ at 16.90 and $18.50 \mathrm{eV}$, respectively, for $\operatorname{Hf} 4 f_{7 / 2}$ and $\mathrm{Hf} 4 f_{5 / 2}$ [6]. Nevertheless, these peaks, in the vicinity of $\mathrm{Si}$, shift to higher binding energies, i.e. 17-17.5 $\mathrm{eV}$, for $\mathrm{Hf} 4 f_{7 / 2}$, which can be attributed to $\mathrm{HfSi}_{\mathrm{x}} \mathrm{O}_{\mathrm{y}}$. It can be inferred that the peaks corresponding to initial etching cycles belong to $\mathrm{HfO}_{2}$ mode, while the peaks start to be shifting to higher binding energy side after the 5th etching cycle. Therefore, it is clear and also supported by the FTIR spectra (Fig. 2) that $\mathrm{HfSi}_{\mathrm{x}} \mathrm{O}_{\mathrm{y}}$ mode is effective for a thick layer until around 10th etching cycle. Then, the peaks again start to be shown around the position corresponding to $\mathrm{HfO}_{2}$ mode and last until the substrate is reached.

Kirsch et al. pointed out two extra features at 15.0 and $16.6 \mathrm{eV}$ in Hf $4 \mathrm{f}$ XPS spectra. They concluded that these small shoulders correspond to Hf-Si bonding [24]. Similarly, Fang et al. declared that the $\mathrm{Hf} 4 \mathrm{f}$ peak shifted to lower binding energy as well as an additional feature appeared at $14.85 \mathrm{eV}$ corresponding to $\mathrm{Hf}-\mathrm{Si}$ bonds at the interface [25]. It is clear from Fig. 4(a) that these shoulder like peaks in $\mathrm{Hf} 4 \mathrm{f}$ spectra do not exist in this study. Therefore, it can be concluded that there is no indication for the presence of $\mathrm{HfSi}_{\mathrm{x}}$.

XPS depth profile of Si $2 p$ signals of reactively sputtered Hf-oxide film on (100) $p$-Si substrate with native oxide is given in Fig. 4(b). It is well known that the signals obtained around $99.3 \mathrm{eV}$ is the result of elemental (metallic) $\mathrm{Si}\left(\mathrm{Si}^{0}\right)$, while the higher binding energies till around $104 \mathrm{eV}$ correspond to the oxidation states of Si. From these, however, the lower binding energy ones closer to the metallic Si are suboxides, and the highest energy one corresponds to the $\mathrm{Si}^{4+}$ [2]. It is seen that elemental $\mathrm{Si}^{0}$ is started to be seen at the very surface layers, i.e. starting from the 4 th etching cycle and continuing till the depth of the oxide having its intensity getting lowered but at a detectable level. However, after some level of depth like 10th etching cycle, it started to be increased again gradually reaching to the same intensity levels of oxide form of $\mathrm{Si}$, i.e. $\mathrm{SiO}_{\mathrm{x}}$ and being dominant mode after the 12th cycle. Therefore, it can be inferred from XPS depth profiling, as well as confirmed with ellipsometric analysis, that there is a very broad interfacial oxide region since the substrate is reached after the 17th etching cycle of XPS spectra. This behavior of having a reasonable amount of elemental Si very close to the top layers of grown hafnium 

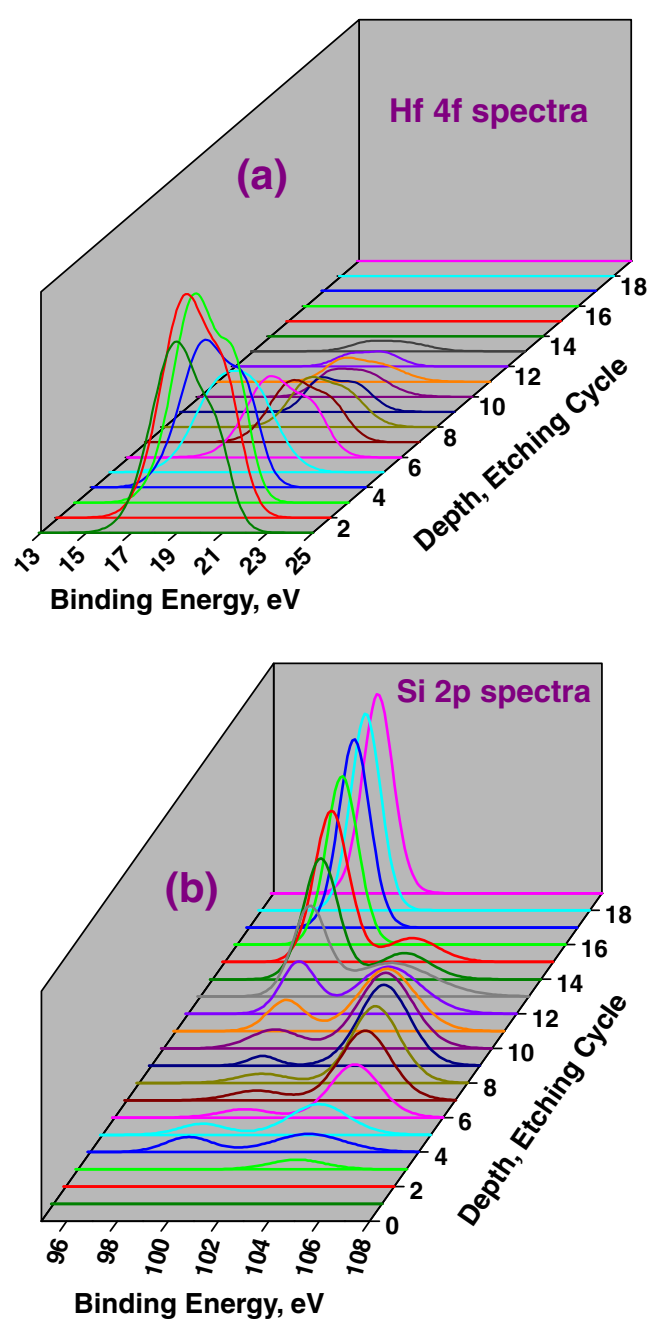

Fig. 4. XPS depth profiling spectra for (a) Hf $4 f$, (b) Si $2 p$.

oxide film gives the idea of causing elementally active sputtered $\mathrm{Hf}$ radicals decompose the native $\mathrm{SiO}_{2}$ to form elemental silicon atom and oxygen molecule and/or atom explicitly. As a result, the oxygen gained from the native $\mathrm{SiO}_{2}$ oxide is used to form $\mathrm{HfO}_{2}$ while leaving unbonded elemental Si atoms or Si-suboxide behind [3].

\subsection{SE optical properties}

\subsubsection{Substrate temperature effect}

SE measurements with respect to wavelength over the used spectral range of 300-850 nm at $70^{\circ}$ incidence angle of light on $\mathrm{HfO}_{2}$ film grown on $p$-Si (100) were made under vacuum conditions. Sputtered grown $\mathrm{HfO}_{2}$ film on Si substrate was modeled as Air/ $/ \mathrm{HfO}_{2}-\mathrm{film} / \mathrm{SiO}_{2} / \mathrm{c}-\mathrm{Si}(100)$. Thickness and refractive index of $\mathrm{HfO}_{2}$ film as well as thickness of $\mathrm{SiO}_{2}$ film were left as variable for fitting process. Then, the constructed model was fitted for $\mathrm{HfO}_{2}$ thin film using Cauchy dispersion relation, since $\mathrm{HfO}_{2}$ is transparent in the spectral range of interest, i.e. $\lambda>350 \mathrm{~nm}$. The equations for Cauchy dispersion model are,

$n(\lambda)=n_{0}+C_{0} \frac{n_{1}}{\lambda^{2}}+C_{1} \frac{n_{2}}{\lambda^{4}}$

$k(\lambda)=k_{0}+C_{0} \frac{k_{1}}{\lambda^{2}}+C_{1} \frac{k_{2}}{\lambda^{4}}$

where $C_{0}=10^{2}$ and $C_{1}=10^{7}$ with $\lambda$ is in units of $n m$ with $n_{0}, n_{1}, n_{2}$, $k_{0}, k_{1}, k_{2}$ are numbers to be fitted with respect to wavelength.
Fig. 5 shows the substrate temperature effect during growth on refractive indices of sputter grown films. These films were grown under the conditions of $30 \mathrm{~W}$ of DC sputter power, $\mathrm{O}_{2} / \mathrm{Ar}$ gas ratio of 0.4 and $5 \mathrm{~min}$ sputtering time. Refractive index with respect to SE wavelength ranging from 300 to $850 \mathrm{~nm}$ was measured for the substrate temperatures of 100,150 and $200{ }^{\circ} \mathrm{C}$. It is seen from Table 1(a) that there is a highly positive effect of substrate temperature increments on refractive index increments of grown $\mathrm{HfO}_{2}$ film. It should be realized that this effect is even much more emphasized for higher substrate temperatures. The refractive index of grown hafnium-oxide layer is obtained as 1.54 for $100^{\circ} \mathrm{C}$, while it increases 1.68 for $150{ }^{\circ} \mathrm{C}$ at the wavelength of $632.8 \mathrm{~nm}$. Furthermore, the measured refractive index as being 1.83 for the films grown at $200{ }^{\circ} \mathrm{C}$ is the one closest to that of bulk $\mathrm{HfO}_{2}$ value, i.e. 2.1 , at $632.8 \mathrm{~nm}$. Therefore, the results infer us that the highest substrate temperature choice used in our experiments, i.e. $200{ }^{\circ} \mathrm{C}$, results in the best refractive index spectra obtained for DC sputtered grown films.

\subsubsection{Oxygen to argon gas ratio effect}

Fig. 6 shows the $\mathrm{O}_{2} / \mathrm{Ar}$ gas ratio effect on refractive index for the wavelength range from 300 to $850 \mathrm{~nm}$ of sputter grown films. These films were grown under the conditions of $30 \mathrm{~W}, 200{ }^{\circ} \mathrm{C}$ and $5 \mathrm{~min}$, respectively, for DC sputtering power, substrate temperature and sputtering time. It is detected that the refractive index value at $632.8 \mathrm{~nm}$ wavelength increases when $\mathrm{O}_{2} / \mathrm{Ar}$ gas ratio decreases. Refractive index values of grown Hf-oxide films at the wavelength of $632.8 \mathrm{~nm}$ are obtained as $1.79,1.83,1.85$ for $\mathrm{O}_{2} / \mathrm{Ar}$ gas ratio values, respectively, of $0.5,0.4,0.2$. Therefore, the results show us that the refractive index values increase depending inversely on oxygen gas amount inside the vacuum system, and the lowest used oxygen to argon gas ratio of 0.2 gives the best refractive index values obtained for DC sputter grown hafnium-oxide films.

The more probable reason of why the refractive index of grown $\mathrm{Hf}$-oxide film gets increased when the $\mathrm{O}_{2} / \mathrm{Ar}$ ratio gets lowered could be best described with a following explanation: Since the increased amount of oxygen gas in the vacuum chamber results in an increment of the scattering centers of sputtered Hf atoms, therefore, some part of $\mathrm{Hf}$ atoms are prevented from reaching to the substrate. Additionally, when the oxygen quantity in the $\mathrm{O}_{2} / \mathrm{Ar}$ ratio is increased, then oxygen diffusion into the interfacial region increases resulting in an undesired interfacial layer formation between the high- $\kappa$ thin film and Si substrate. Similar results can also be detected from the literature that, not only the oxygen diffusion rate increases but the growth rate of $\mathrm{HfO}_{2}$ film is decreased at high levels of oxygen concentrations [20]. Therefore, the increased amount of oxygen

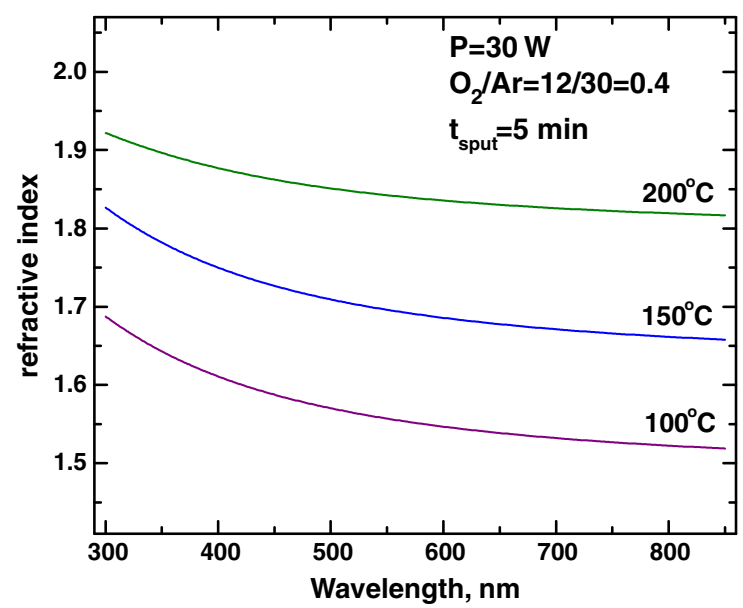

Fig. 5. Substrate temperature effect on refractive index of DC sputter grown hafniumoxide films. 
Table 1

SE fitting results given at the wavelength of $632.8 \mathrm{~nm}$ for; (a) $30 \mathrm{~W}$ sputter power for 5 min at the gas ratio of 0.4 , (b) 0.2 gas ratio at the substrate temperature of $200{ }^{\circ} \mathrm{C}$ for $5 \mathrm{~min}$.

\begin{tabular}{|c|c|c|c|}
\hline \multicolumn{4}{|l|}{ (a) } \\
\hline $\begin{array}{l}\text { Substrate temperature } \\
{ }^{\circ} \mathrm{C}\end{array}$ & Layer property & $\begin{array}{l}\text { Thickness }(\mathrm{d}) \\
\mathrm{nm}\end{array}$ & $\begin{array}{l}\text { Refractive index } \\
\text { (n) }\end{array}$ \\
\hline 100 & $\begin{array}{l}\mathrm{HfO}_{2} \\
\text { Silicon-oxide }\end{array}$ & $\begin{array}{r}17.70 \\
5.87\end{array}$ & $\begin{array}{l}1.54 \\
-\end{array}$ \\
\hline 150 & $\begin{array}{l}\mathrm{HfO}_{2} \\
\text { Silicon-oxide }\end{array}$ & $\begin{array}{l}14.83 \\
10.45\end{array}$ & $\begin{array}{l}1.68 \\
-\end{array}$ \\
\hline 200 & $\begin{array}{l}\mathrm{HfO}_{2} \\
\text { Silicon-oxide }\end{array}$ & $\begin{array}{l}16.13 \\
11.55\end{array}$ & $\begin{array}{l}1.83 \\
-\end{array}$ \\
\hline (b) & & & \\
\hline $\begin{array}{l}\text { Sputter power } \\
\text { Watt }\end{array}$ & Layer property & $\begin{array}{l}\text { Thickness (d) } \\
\mathrm{nm}\end{array}$ & $\begin{array}{l}\text { Refractive index } \\
\text { (n) }\end{array}$ \\
\hline 20 & $\begin{array}{l}\mathrm{HfO}_{2} \\
\text { Silicon-oxide }\end{array}$ & $\begin{array}{r}16.62 \\
3.57\end{array}$ & $\begin{array}{l}1.70 \\
-\end{array}$ \\
\hline 25 & $\begin{array}{l}\mathrm{HfO}_{2} \\
\text { Silicon-oxide }\end{array}$ & $\begin{array}{l}11.82 \\
12.96\end{array}$ & $\begin{array}{l}1.72 \\
-\end{array}$ \\
\hline 30 & $\begin{array}{l}\mathrm{HfO}_{2} \\
\text { Silicon-oxide }\end{array}$ & $\begin{array}{l}15.59 \\
12.66\end{array}$ & $\begin{array}{l}1.85 \\
-\end{array}$ \\
\hline
\end{tabular}

ratio affects the evolution of hafnium-oxide film in a negative manner, i.e. resulting in a porous film structure as well as an uncontrollable interfacial layer formation. As a result, the oxidation process is obtained as more effective at lower oxygen contents compared to those of higher oxygen contents. The future task would be to obtain the characteristics of grown $\mathrm{HfO}_{2}$ film for $\mathrm{O}_{2} / \mathrm{Ar}$ gas ratio of lower than 0.2 .

\subsubsection{Sputter power effect}

Fig. 7 shows the sputter power effect on the refractive index values of sputter grown films in the wavelength range from 300 to $850 \mathrm{~nm}$. These films were grown under the conditions of $200{ }^{\circ} \mathrm{C}, 0.2,5 \mathrm{~min}$, respectively, for substrate temperature, oxygen to argon gas ratio and sputtering time. Refractive index and thickness values of layers at the wavelength of $632.8 \mathrm{~nm}$, respectively, for 20,25, and $30 \mathrm{~W}$ DC sputter powers are given in Table 1(b). It is obvious that the refractive index values of hafnium-oxide films grown under the sputter powers of 20 and $25 \mathrm{~W}$ are too much lower than that of bulk value of $\mathrm{HfO}_{2}$. However, having been a value of 1.85 , the refractive index for $30 \mathrm{~W}$ is very close to that of bulk $\mathrm{HfO}_{2}$. It can be concluded that DC sputter power of $30 \mathrm{~W}$ is a threshold to produce hafnium oxide films whose

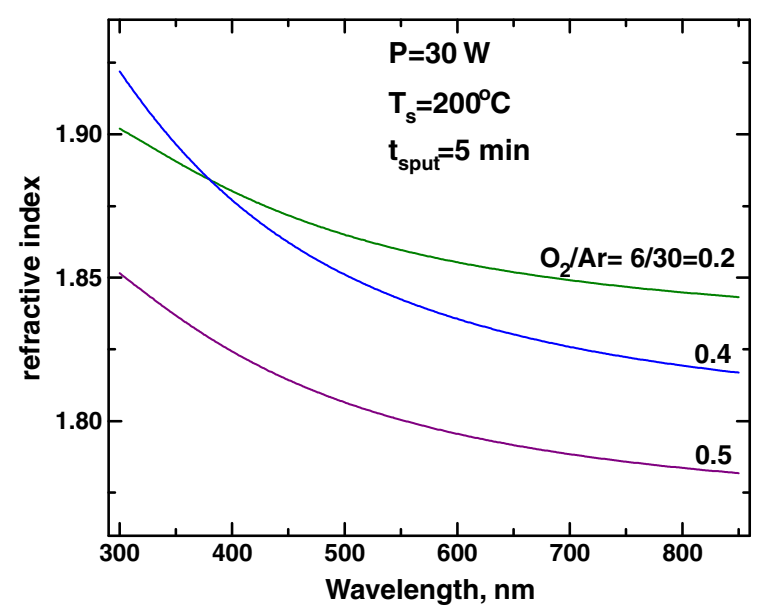

Fig. 6. Oxygen to argon gas ratio effect on refractive index of DC sputter grown hafnium-oxide films.

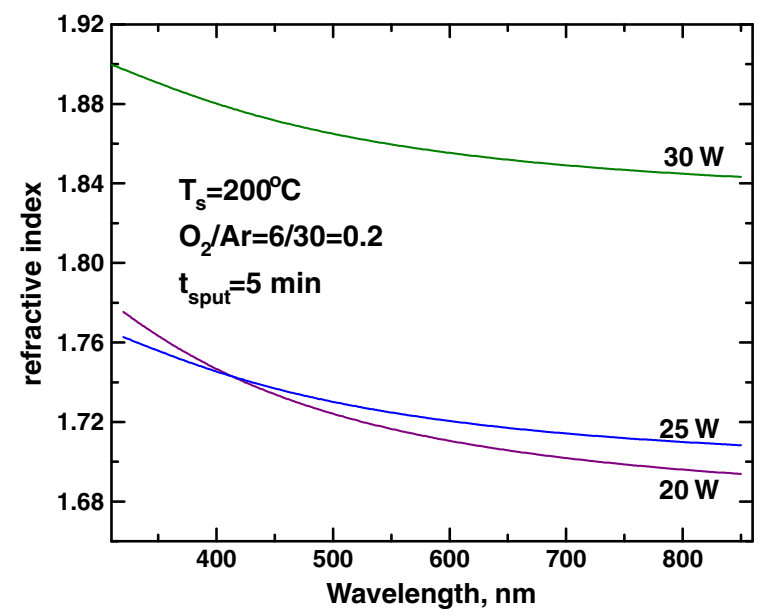

Fig. 7. Sputter power effect on the refractive index of DC sputter grown hafnium-oxide films.

density is being close to that of bulk $\mathrm{HfO}_{2}$. Moreover, DC sputtering power values should be around $30 \mathrm{~W}$ and/or little more to grow dense enough hafnium-oxide films.

\section{Conclusion}

$\mathrm{HfO}_{2} / \mathrm{SiO}_{2} / \mathrm{p}-\mathrm{Si}(100)$ stacks were studied in terms of structural and optical analyses by means of FTIR, XRD, XPS depth profiling and Spectroscopic Ellipsometry. FTIR for structural and bonding analyses as well as XRD for crystalline structural analyses were studied for $\mathrm{Hf}$ oxide films grown at 100,150 , and $200{ }^{\circ} \mathrm{C}$ with $\mathrm{O}_{2} / \mathrm{Ar}$ gas ratio of 0.4 for $5 \mathrm{~min}$ at $30 \mathrm{~W}$ of DC sputtering power. FTIR analyzing technique confirms that the films grown at $200{ }^{\circ} \mathrm{C}$ have better results in terms of having definite $\mathrm{Hf}-\mathrm{O}$ structural bondings, however, the films grown at lower substrate temperatures do not have the explicit peaks decisive to $\mathrm{HfO}_{2}$ films. XRD results of the same property films with FTIR analyzing technique show that the films have amorphous structure grown at the substrate temperature of $100^{\circ} \mathrm{C}$, while the polycrystalline structure starts to be seen around $150^{\circ} \mathrm{C}$ and it increases little more for films grown at the substrate temperature of $200{ }^{\circ} \mathrm{C}$.

The FTIR, XRD and SE results with respect to substrate temperatures show us that when the substrate temperature gets lowered, then the grown $\mathrm{HfO}_{2}$ film is mainly amorphous. Its intensity increases very tiny for $150{ }^{\circ} \mathrm{C}$, while it is recognizable enough at $200^{\circ} \mathrm{C}$. Additionally, the main FTIR peaks reflecting $\mathrm{Hf}-\mathrm{O}$ bonds are recognized well when the substrate temperature increases, however, the crystallization is detected at the same time. From SE measurements, a highly positive effect of substrate temperature increments on refractive index increments of grown film is detected. However, refractive index is getting extremely low, i.e. 1.54 at $632.8 \mathrm{~nm}$, for $100{ }^{\circ} \mathrm{C}$ substrate temperature case. Even though the refractive index is increased for the choice of $200{ }^{\circ} \mathrm{C}$ substrate temperature, the crystalline structure for grown $\mathrm{HfO}_{2}$ film is detected from not only XRD but also SE measurements. Since the crystalline structure for high- $\kappa$ films is not a desired property, the substrate temperature was restricted to be at $200{ }^{\circ} \mathrm{C}$. However, for a future task, the substrate temperature higher than $200{ }^{\circ} \mathrm{C}$ can be studied in order to obtain the optical as well as structural properties of grown film.

XPS depth profiling spectra were studied for the Hf oxide film grown at $200{ }^{\circ} \mathrm{C}$ with $\mathrm{O}_{2} / \mathrm{Ar}$ gas ratio of 0.4 for $5 \mathrm{~min}$ at $30 \mathrm{~W}$ of DC sputtering power. The results show us that there is an extremely thin $\mathrm{HfO}_{2}$ layer on top of a respectively broad interfacial layer formed mainly from Si suboxide and Hf-silicate. It is clearly explained by an XPS depth profiling spectra that the formation of $\mathrm{HfSi}_{\mathrm{x}}$ was eliminated since there is no direct contact of sputtered $\mathrm{Hf}$ with $\mathrm{SiO}_{2} / \mathrm{Si}$ substrate. 
The results infer that there existed a very thin perfect Hf-oxide layer, later $\mathrm{Si}-\mathrm{Si}$ bonds are detected even before Si suboxide layer is reached and then Si substrate is reached. Since Si-Si bonds were measured just before Si-oxide is reached, it can be realized that highly reactive sputtered $\mathrm{Hf}$ atoms consume some of the oxygen atoms from the underlying $\mathrm{SiO}_{2}$ to form hafnium-oxide by leaving $\mathrm{Si}-\mathrm{Si}$ bonds behind [3]. Our results also confirm what Yamamoto et al. revealed with their experiment that the oxygen radicals oxidize the Hf metal more selectively than Si substrate [11].

Finally, we have additionally obtained the best oxidation conditions for Hf-oxide films in terms of SE optical analyzing technique overall the used physical growth parameters, i.e. substrate temperature, oxygen to argon gas ratio, and DC sputtering power. The SE optical analyzing technique results in $200{ }^{\circ} \mathrm{C}, 0.2$, and $30 \mathrm{~W}$ respectively for the substrate temperature, oxygen to argon gas ratio and DC sputtering power as the best oxidation conditions from the overall used parameters.

\section{Acknowledgements}

This research was supported mainly by The Scientific and Technological Research Council of Turkey (TUBITAK) with project number of $107 \mathrm{~T} 117$ and partially by Izmir Institute of Technology with research project number of 2008 IYTE 37.

\section{References}

[1] G.D. Wilk, R.M. Wallace, J.M. Anthony, J. Appl. Phys. 89 (2001) 5243.

[2] G. Aygun, E. Atanassova, K. Kostov, R. Turan, J. Non-Cryst. Solids 352 (2006) 3134.
[3] G. Aygun, I. Yildiz, J. Appl. Phys. 106 (2009) 014312.

[4] G. Aygun, R. Turan, Thin Solid Films 517 (2008) 994.

[5] S. Hayashi, K. Yamamoto, Y. Harada, R. Mitsuhashi, K. Eriguchi, M. Kubota, M. Niwa, Appl. Surf. Sci. 216 (2003) 228.

[6] Q. Fang, J.-Y. Zhang, Z. Wang, M. Modreanu, B.J. O'Sullivan, P.K. Hurley, T.L. Leedham, D. Hywel, M.A. Audier, C. Jimenez, J.-P. Senateur, I.W. Boyd, Thin Solid Films 453-454 (2004) 203.

[7] R. Thielsch, A. Gatto, J. Heber, N. Kraiser, Thin Solid Films 410 (2002) 86.

[8] J. Kim, S. Kim, H. Kang, J. Choi, H. Jeon, M. Cho, K. Chung, S. Back, K. Yoo, C. Bae, J. Appl. Phys. 98 (2005) 094504.

[9] J. Zhu, Z.G. Liu, Y. Feng, J. Phys. D Appl. Phys. 36 (2003) 3051.

[10] G. Aygun, E. Atanassova, A. Alacakir, L. Ozyuzer, R. Turan, J. Phys. D Appl. Phys. 37 (2004) 1569.

[11] K. Yamamoto, S. Hayashi, M. Niwa, M. Asai, S. Horii, H. Miya, Appl. Phys. Lett. 83 (2003) 2229.

[12] R. Tan, Y. Azuma, I. Kojima, Appl. Surf. Sci. 222 (2004) 346.

[13] H.G. Tompkins, W.A. McGahan, Spectroscopic Ellipsometry and Reflectometry, John Wiley and Sons, New York, 1999.

[14] H. Fujiwara, Spectroscopic Ellipsometry: Principles and Applications, John Wiley \& Sons, England, 2007.

[15] G. He, L.D. Zhang, Q. Fang, J. Appl. Phys. 100 (2006) 083517.

[16] T.C. Chen, C.Y. Peng, C.H. Tseng, M.H. Liao, M.H. Chen, C.I. Wu, M.Y. Chern, P.J. Tzeng, C.W. Liu, IEEE Trans. Electron Devices 54 (2007) 759.

[17] D.A. Neumayer, E. Cartier, J. Appl. Phys. 90 (2001) 1801.

[18] A. Deshpande, R. Inman, G. Jursich, C. Takoudis, Microelectron. Eng. 83 (2006) 547.

[19] E. Atanassova, G. Aygun, R. Turan, Tz. Babeva, J. Vac. Sci. Technol. A 24 (2006) 206.

[20] L. Pereia, A. Marques, H. Aguas, N. Nedev, S. Georgiev, E. Fortuna, R. Martins, Mater. Sci. Eng. B 109 (2004) 89.

[21] S.W. Nam, J.H. Yoo, S. Nam, H.J. Choi, D. Lee, D.H. Ko, J.H. Moon, J.H. Ku, S. Choi, J. Non-Cryst. Solids 303 (2002) 139.

[22] G. He, M. Liu, L.Q. Zhu, M. Chang, Q. Fang, L.D. Zhang, Surf. Sci. 576 (2005) 67.

[23] G. Tian, S. Wu, K. Shu, L. Qin, J. Shao, Appl. Surf. Sci. 253 (2007) 8782.

[24] P.D. Kirsch, C.S. Kang, J. Lozano, J.C. Lee, J.G. Ekerdt, J. Appl. Phys. 91 (2002) 4353.

[25] Q. Fang, J.Y. Zhang, Z. Wang, M. Modreanu, B.J. O'Sullivan, P.K. Hurley, T.L. Leedham, D. Hywel, M.A. Audier, C. Jimenez, J.P. Senateur, Ian W. Boyd, Thin Solid Films 453-454 (2004) 203. 